\title{
ANALISIS PENERAPAN GREEN ACCOUNTING BERBASIS UNIVERSITY SOCIAL RE- SPONSIBILITY (USR) PADA UNIVERSITAS RIAU KEPULAUAN DAN UNIVERSITAS IN- TERNASIONAL BATAM
}

\section{ANALYSIS OF APPLICATION BASED GREEN ACCOUNTING UNIVERSITY SOCIAL RESPONSIBILITY (USR) IN RIAU KEPULAUAN UNIVERSI- TY AND BATAM INTERNATIONAL UNIVERSITY}

\author{
Ravika Permata Hati ${ }^{1}$ \\ ${ }^{I}$ (Akuntansi, Ekonomi, Universitas Riau Kepulauan, Indonesia \\ ${ }^{1}$ ravika.fekon@unrika.ac.id
}

\begin{abstract}
Abstrak
Penelitian ini bertujuan untuk mengetahui apakah terdapat perbedaan perhatian, tanggung jawab, pelaporan akuntansi lingkungan, dan audit lingkungan antara Universitas Riau Kepulauan dan Universitas Internasional Batam. Penelitian ini menggunakan data kuantitatif. Populasi penelitian ini meliputi pejabat struktural pada Universitas Riau Kepulauan dan Universitas Internasional Batam dengan masing-masing berjumlah 60 orang. Teknik pengambilan sampel dengan menggunakan teknik sampel acak (random sampling). Metode pengumpulan data menggunakan kuesioner dengan menggunakan Google Form. Metode analisis data menggunakan Independent Sample T-Test dan Mann Whitney U-Test dengan alat analisis SPSS 20. Hasil Penelitian ini menunjukkan bahwa terdapat perbedaan antara Universitas Riau Kepulauan dan Universitas Internasional Batam untuk variabel Keterlibatan dan Pelaporan Lingkungan, sedangkan tidak terdapat perbedaan yang signifikan antara Universitas Riau Kepulauan dan Universitas Internasional Batam untuk variabel Kesadaran dan Audit Lingkungan.
\end{abstract}

Kata Kunci ; Green Accounting; University Social Responsibility; Kuantitatif

\begin{abstract}
This study aims to determine whether there are differences in attention, responsibility, environmental accounting reporting, and environmental auditing between the University of Riau Islands and the International University of Batam. This research uses quantitative data. The population of this study includes structural officials at the University of Riau Islands and International University of Batam with each of them amounted to 60 people. Technique of sampling by using technique of random sampling (random sampling). Methods of data collection using questionnaires using Google Form. Methods of data analysis using Independent Sample T-Test and Mann Whitney U-Test with SPSS 20 analysis tool. The results of this study indicate that there is a difference between the University of Riau Islands and the International University of Batam for the Environmental Involvement and Reporting variables, whereas there is no significant difference between the Riau Archipelago University and the International University of Batam for the Awareness and Environmental Audit
\end{abstract}

Keywords ; Green Accounting; University Social Responsibility; Kuantitatif 


\section{PENDAHULUAN}

Isu-isu mengenai lingkungan mulai banyak dibicarakan dekade terakhir. Masyarakat mulai sadar betapa pentingnya kelestarian lingkungan untuk kelangsungan hidup manusia dimasa depan. Isu-isu lingkungan langsung maupun tidak langsung mempengaruhi kegiatan bisnis pada suatu organisasi. Hal ini tentu memaksa kegiatan bisnis perusahaan untuk menyesuaikan diri terhadap isu lingkungan. Bentuk penyesuaian kegitan bisnis perusahaan terhadap isu lingkungan adalah akuntansi.

Akuntansi sebagai calculate science yaitu akuntansi menerapkan perhitungan biaya lingkungan dalam implementasi ilmunya untuk tujuan transparasi perusahaan dalam mengungkapkan informasi lingkungan sebagai dampak dari aktivitas bisnis yang dilakukan perusahaan (Kartikasari, 2012: 1). Ilmu akuntansi yang mempelajari khusus di bidang lingkungan disebut dengan green accounting atau juga dikenal dengan enviromental accounting.

Green accounting berkaitan dengan informasi lingkungan dan sistem audit lingkungan dan telah didefinisikan sebagai 'identifikasi, pelacakan, analisis, serta pelaporan dan informasi biaya yang terkait dengan aspek lingkungan dari suatu organisasi. Peran utama green accounting adalah untuk mengatasi masalah lingkungan sosial, serta memiliki dampak pada pencapaian pembangunan berkelanjutan dan lingkungan di negara manapun, yang mempengaruhi perilaku perusahaan dalam menghadapi isu-isu tanggung jawab sosial dan lingkungan. Selain itu, green accounting juga digunakan sebagai upaya perusahaan untuk membantu dalam mencapai tujuan perusahaan terhadap tanggung jawab kepada stakeholder perusahaan (Astiti, 2014).
Implementasi University Social Responsibility merupakan perwujudan komitmen yang dibangun oleh perguruan tinggi untuk memberikan kontribusi pada peningkatan kualitas kehidupan masyarakat. Perguruan tinggi juga bertanggung jawab terhadap dunia pendidikan dan menyelenggaraan tanggung jawab sosial yang disinergikan dengan penerapan Tri Dharma perguruan tinggi, sehingga menjadi satu kesatuan yang terintegrasi terhadap kesejahteraan masyarakat (Rahman, 2012).

Universitas Riau Kepulauan sendiri sesuai dengan visi nya yaitu "Menjadi universitas yang menghasilkan sumber daya manusia yang unggul, kreatif dan mandiri" pihak perguruan tinggi tentu saja terus meningkatkan kualitas dan fasilitas kampus agar tercapainya tujuan yang diinginkan. Sedangkan, Universitas Internasional Batam merupakan salah satu perguruan tinggi terbesar di Pulau Batam yang berpartisipasi dalam pembangunan Nasional dan memberikan pendidikan masyarakat.

Bentuk kepedulian lingkungan oleh pihak universitas antara lain adalah beasiswa bagi mahasiswa berprestasi, beasiswa bagi masyarakat kurang mampu, penghijauan di lingkungan kampus, ketersediaan lapangan parkir, kegiatan-kegiatan universitas yang berhubungan dengan lingkungan dan lain sebagainya. Dalam menjalankan tanggung jawab sosial universitas di bidang lingkungan, maka universitas akan melakukan beberapa aktifitas yang berhubungan dengan lingkungan. Dengan melakukan aktivitas tersebut, universitas akan membutuhkan biaya yang disebut dengan biaya lingkungan.

\section{TINJAUAN PUSTAKA}

Akuntansi Lingkungan

Green accountings atau environ-

mental accounting (akuntansi lingkungan) merupakan penggabungan in- 
formasi manfaat dan biaya lingkungan kedalam macam-macam praktik akuntansi dan penggabungan biaya lingkungan kedalam keputusan bisnis (Wahyudi, 2012). Konsep ini mulai berkembang sejak tahun 1970- an. Pada tahun 1990-an, IASC (The International 'Accounting Standards Committee) mengembangkan konsep tentang prinsip akuntansi internasional, termasuk di dalamnya pengembangan akuntansi lingkungan. AICPA (American Institute of Certified Public Accountant) juga mengeluarkan prinsipprinsip universal tentang audit lingkungan.

Akuntansi lingkungan juga merupakan suatu bidang yang terus berkembang dalam mengidentifikasikan pengkuran-pengkuran dan mengkomunikasikan biaya-biaya aktual perusahaan atau dampak potensial lingkungannya. Biaya biaya ini meliputi biaya pembersihan atau perbaikan tempat-tempat yang terkontaminasi, biaya pelestarian lingkugan, biaya hukuman dan pajak, biaya pencegahan populasi dan biaya manajemen pemborosan (Arfan, 2008 : 15-16).

\section{Fungsi dan Peran Akuntansi Lingkungan} Menurut Arfan (2008: 18) dijelaskan bahwa pentingnya penggunaan akuntasni lingkungan bagi perusahaan atau organisasi lainnya dijelaskan dalam fungsi dan peran akuntansi lingkungan. Fungsi dan peran ini dibagi ke dalam dua bentuk:

1. Fungsi Internal: fungsi yang berkaitan dengan pihak internal perusahaan sendiri.

2. Fungsi Eksternal: fungsi yang berkaitan dengan pelaporan keuangan. SFAC No.1 menjelaskan bahwa pelaporan keuangan memberikan informasi yang bermanfaat bagi inves- tor dan kreditor, dan pemakai lainnya dalam pengambilan keputusan secara rasional.

\section{Tujuan Penerapan Akuntansi Ling- kungan}

1. Sebagai alat manajemen lingkungan akuntasi lingkungan digunakan untuk menilai keefektifan kegiatan konservasi berdasarkan ringkasan dan klasifikasi biaya konservasi lingkungan.

2. Sebagai alat komunikasi dengan publik, akuntansi lingkungan digunakan untuk menyampaikan dampak negatif lingkungan, kegiatan konservasi lingkungan dan hasilnya kepada publik.

\section{Peraturan yang Terkait dengan Green Accounting}

1. Undang-Undang No. 23 Tahun 1997 tentang Pengelolaan Lingkungan Hidup. UU ini mengatur tentang kewajiban setiap orang yang berusaha atau berkegiatan untuk menjaga, mengelola, dan memberikan informasi yang benar dan akurat mengenai lingkungan hidup.

2. Undang-Undang No. 40 Tahun 2007 tentang Perseroan Terbatas.

3. Keputusan Ketua Badan Pengawas Pasar Modal dan Lembaga Keuangan No: KEP- 134/BL/2006 tentang Kewajiban Penyampaian Laporan Tahunan bagi Emiten atau Perusahaan Publik.

4. Pernyataan Standar Akuntansi Keuangan (PSAK) No. 32 (Akuntansi Kehutanan) dan No. 33 (Akuntansi Pertambangan Umum). 


\section{University Social Responsibility}

Konsep tanggung jawab sosial atau Corporate Social Responsibilities (CSR) pada perguruan tinggi lebih dikenal dengan istilah University Social Responsibilities (USR). USR pada dasarnya merupakan suatu kebijakan etis yang mempengaruhi kualitas kinerja komunitas perguruan tinggi yang meliputi mahasiswa, pengelola, pengajar dan seluruh karyawan perguruan tinggi melalui manajemen yang bertanggungjawab terhadap dampak pendidikan, kognitif, ketenagakerjaan dan lingkungan yang dihasilkan oleh perguruan tinggi melalui suatu dialog interaktif dengan masyarakat dalam rangka menghasilkan pembangunan manusia yang berkesinambungan. Berdasarkan pendekatan yang berkesinambungan ini, sustainable campus merupakan suatu strategi yang berusaha mengurangi dampak ekologis institusi melalui penggunaan rasional sumber daya dan mengedukasi seluruh komunitas yang ada di perguruan tinggi mengenai etika keberlangsungan.

Dalam menjalankan aktivitas seharihari pada dasarnya terdapat empat dampak yang dihasilkan oleh suatu perguruan tinggi yaitu:

1. Dampak Sosial

Melalui partisipasi komunitas dalam kerjasama yang saling menguntungkan melalui berbagai upaya pengembangan

2. Dampak Pendidikan

Penyiapan mahasiswa untuk menjadi warga Negara yang bertaggungjawab dalam pembangunan yang berkelanjutan.

3. Dampak Kognitif

Tanggungjawab social bagi berbagai aktivitas teknis dan keilmuan perguruan tinggi

4. Dampak Organisasi

Kehidupan perguruan Tinggi yang bertanggung jawab secara social dan lingkungan.

\section{Faktor-faktor Dalam Tanggung Jawab Organisasi Terhadap Akuntansi Ling- kungan}

\section{Kesadaran Lingkungan (Environmen- tal Awareness)}

Hasil penelitian teoritik tentang kesadaran lingkungan hidup dari Neolaka (1991) dalam Amiruddin (2012), menyatakan bahwa kesadaran adalah keadaan tergugahnya jiwa terhadap sesuatu, dalam hal ini lingkungan hidup, dan dapat terlihat pada prilaku dan tindakan masing-masing individu. Lebih lanjut menurut Salim (1982) dalam Amiruddin (2012), kesadaran lingkungan adalah upaya untuk menumbuhkan kesadaran agar tidak hanya tahu tentang sampah, pencemaran, penghijauan, dan perlindungan satwa langka, tetapi lebih dari pada itu semua, membangkitkan kesadaran lingkungan manusia Indonesia khususnya pemuda masa kini agar mencintai tanah air.

Terdapat beberapa faktor yang mempengaruhi kesadaran lingkungan, yaitu

1. Faktor Ketidaktahuan

Ketidaktahuan adalah berlawanan dengan ketahuan atau pengetahuan. Pengetahuan dimulai dengan rasa ingin tahu. Oleh karena itu, rasa ingin tahu merupakan sarana untuk mengumpulkan pengetahuan sebanyak mungkin. Manusia tidak hanya memiliki pengetahuan tetapi mampu menalar, artinya dapat berpikir secara logis dan analitis.

2. Faktor Kemiskinan

Kemiskinan adalah keadaan ketidakmampuan untuk memenuhi kebutuhan hidup minimum. Kemiskinan dianggap sebagai peristiwa sosio ekonomi dimana sumber daya yang ada digunakan untuk memuaskan keinginan yang sedikit, sedangkan yang banyak tidak dapat memenuhi 
kebuutuhan pokoknya sendiri. Kemiskinan merupakan salah satu penyebab rendahnya kualitas penduduk Indonesia, disamping faktor lain seperti tingkat produktivitas, pendidikan, kesehatan dan keadaan sosial ekonomi lainnya.

3. Faktor Kemanusiaan

Manusia adalah mahluk yang berakal budi. Manusia mempunyai kemampuan atau keterampilan untuk memciptakan sebuah dunia baru. Manusia dalam kehidupannya mempunyai kebutuhan yang banyak sekali. Adanya kebutuhan inilah yang mendorong manusia untuk melakukan berbagai tindakan guna memenuhi kebutuhan tersebut.

4. Faktor Gaya Hidup Perkembangan Ilmu Pengetahuan dan Teknologi informasi serta Komunikasi yang sangat cepat, sudah tentu berpengaruh pula terhadap gaya hidup manusia. Perubahan gaya hidup ini adalah suatu hal yang wajar apabila Iptek yang diserapnya memberikan perubahan kearah yang positif dan diterima oleh lingkungan dimana individu/manusia itu berada.

\section{Keterlibatan Lingkungan (Environ- mental Involvement)}

Tanggungjawab dan Keterlibatan Lingkungan adalah komitmen organisasi untuk berperan serta dalam pembangunan ekonomi berkelanjutan guna meningkatkan kualitas kehidupan dan lingkungan yang bermanfaat, baik bagi Perseroan sendiri, komunitas setempat, maupun masyarakat pada umumnya (Musyarofah 2013). Tanggung jawab sosial organisasi timbul sebagai respon atau tindakan proaktif yang dilakukan oleh organisasi terhadap harapan masyarakat atas pelaksanaan kegiatan yang dilakukan.

Tata cara implementasi penerapan Green Accounting berbasis University Social Responsibility dimana dilakukan dengan tim khusus yang dibentuk langsung berada di bawah pengawasan pimpinan perguruan tinggi yang ditunjuk dan melakukan evaluasi pelaksanaan serta mengukur ke efektivitas penerapan.

\section{Laporan Lingkungan (Environ-} mental Reporting)

Pelaporan lingkngan diperlukan untuk proses pengambilan keputusan maupun dalam rangka keperluan keterbukaan informasi material dan relevan mengenai perguruan tinggi.

\section{Audit Lingkungan (Environmental Audit)}

Audit lingkungan adalah alat pemeriksaan komprehensif dalam sistem manajemen lingkungan untuk memverifikasi secara objektif upaya manajemen lingkungan dan dapat membantu mencari langkahlangkah perbaikan guna meningkatkan performasi lingkungan, berdasarkan kriteria yang telah ditetapkan dan merupakan upaya proaktif suatu perusahaan untuk perlindungan lingkungan yang akan membantu perusahan meningkatkan efisiensi dan pengendalian emisi, polutan yang pada akhirnya dapat meningkatkan citra positif dari masyarakat terhadap perusahaan.

Audit lingkungan hidup adalah suatu proses evaluasi yang dilakukan oleh penanggung jawab usaha dan/atau kegiatan untuk menilai tingkat ketaatan terhadap 
persyaratan hukum yang berlaku dan/atau kebijaksanaan dan standar yang ditetapkan oleh penanggung jawab usaha dan/atau kegiatan yang bersangkutan. (Pasal 1 (23), 28, 29 UU No 23/1997).

\section{Model Penelitian}

Hubungan antara berbagai variabel yang menjadi objek penelitian dapat digambarkan dengan model penelitian dapat dilihat pada Gambar 1 sebagai berikut:

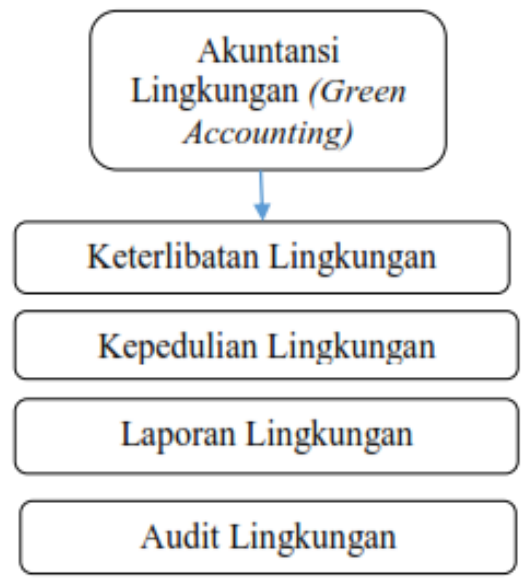

Gambar 1 Model Penelitian

\section{METODE PENELITIAN}

\section{Tahapan Penelitian}

Adapun tahapan dalam penelitian ini adalah sebagai berikut:

1. Menentukan dan merumuskan masalah penelitian serta menentukan tujuan penelitian, pada tahap ini peneliti melakukan studi pendahuluan.

2. Peneliti melakukan telaah pustaka untuk mendapatkan teori yang relevan dan informasi tentang data penelitian terdahulu, kemudian peneliti menetapkan hipotesis.
3. Pada tahap ini peneliti mulai dengan menentukan sumber data yang berkaitan dengan permasalahan dan pengumpulan data dilakukan dengan menggunakan metode Kuesioner yang ditujukan kepada pejabat (stakeholder) di Universitas Riau Kepulauan dan Universitas Internasional Batam.

4. Analisis dan penyajian data, yaitu menganalisis data dan akhirnya ditarik suatu kesimpulan.

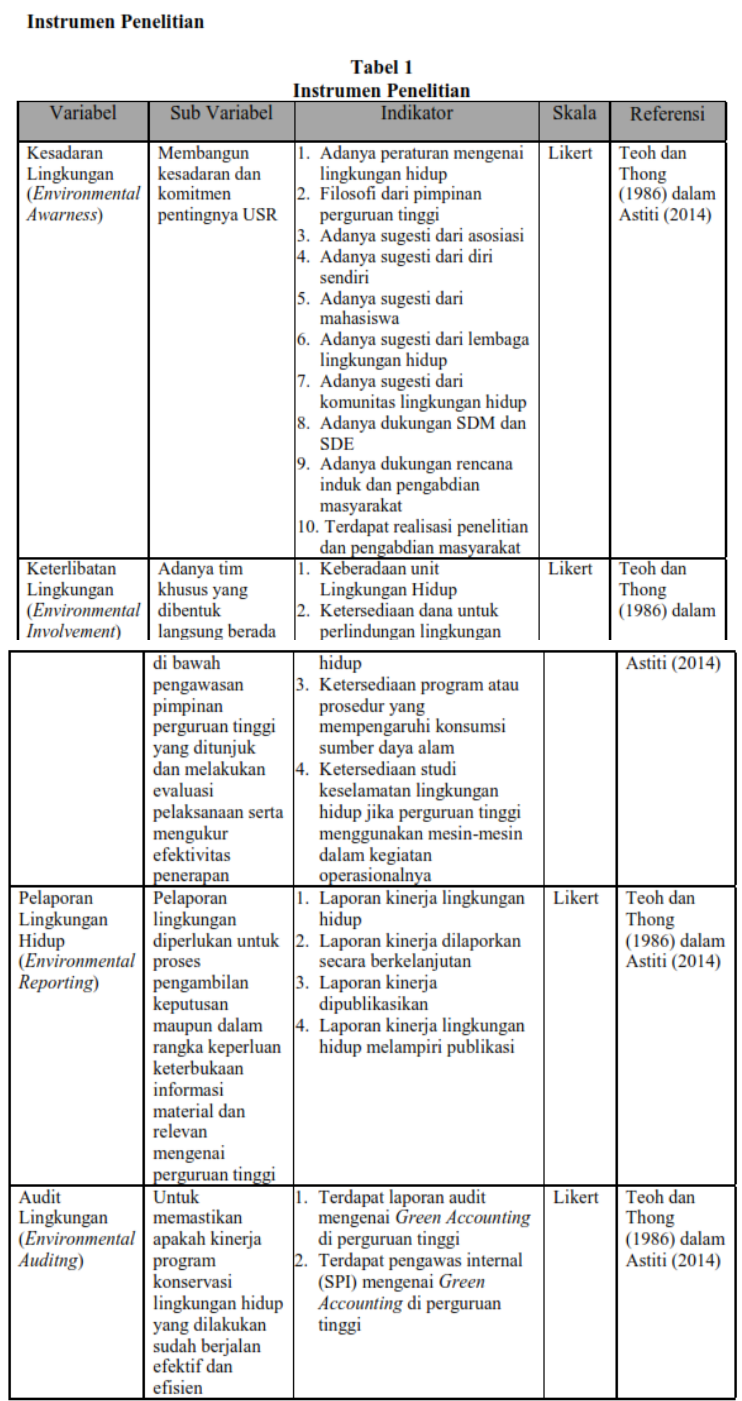

Pengukuran unsur unsur implementasi Green Acounting berbasis University 
Social Responsibility di Universitas Riau Kepulauan dilakukan dengan menggunakan kuesioner skala likert. Menurut Sugiyono (2017:93) menjelaskan bahwa skala likert digunakan untuk mengukur sikap, pendapat, dan persepsi seseorang atau sekelompok orang tentang fenomena sosial. Dalam penelitian, fenomena sosial ini telah ditetapkan secara spesifik oleh peneliti, yang selanjutnya disebut sebagai variabel penelitian.

\section{Metode dan Desain Penelitian}

Metode penelitian yang digunakan

adalah metode kuantitatif dengan melakukan analisis data dengan teknik uji beda Independent sampel T-test dan Mann Whitney $U$ -

Test.

\section{Sumber Data dan Sampel Penelitian}

Sumber data dalam penelitian ini adalah data primer. Data primer dalam penelitian ini diperoleh melalui kuesioner yang disebarkan kepada para pejabat (stakeholder) pada Universitas Riau Kepulauan dan Universitas Internasional Batam.

Teknik pengambilan sampel dengan menggunakan teknik simple random sampling, yaitu mengambil sampel secara acak tanpa memperhatikan strata. Penulis menggunakan tingkat kesalahan sebesar $5 \%$.

\section{Analisis Data}

Teknik analisa data adalah cara yang digunakan dalam mengolah data yang telah dikumpulkan dalam penelitian untuk membuktikan hipotesis yang diajukan. Analisis data yang penulis gunakan dalam penelitian ini adalah sebagai berikut :

1. Deskripsi Kesadaran lingkungan (Environmental Awareness)
Kesadaran Lingkungan terdiri dari 10 item yang pada umumnya telah terdapat beragam dukungan.

2. Deskripsi Keterlibatan Lingkungan (Environmental Involvement) Keterlibatan Lingkungan terdiri dari 4 item yang pada umumnya telah terdapat beragam dukungan.

3. Deskripsi Laporan Lingkungan (Environmental Reporting) Pelaporan Lingkungan terdiri dari 4 item yang pada umumnya telah terdapat beragamdukungan.

Deskripsi Audit Lingkungan (Environmental Audit) Audit Lingkungan terdiri dari 2 item yang pada umumnya telah terdapat beragam dukungan.

\section{HASIL PENELITIAN DAN PEMBAHA- SAN}

Hasil penelitian menunjukkan bahwa variabel Keterlibatan Lingkungan dan Pelaporan Lingkungan dengan menggunakan uji Independent Sample T Test memiliki perbedaan yang signifikan antara Universitas Riau Kepulauan dengan Universitas Internasional Batam. Sedangkan, untuk variabel Kesadaran dan Audit Lingkungan tidak memiliki perbedaan yang signifikan antara Universitas Riau Kepulauan dengan Universitas Internasional Batam. Hal ini dapat dilihat pada tabel berikut ini. 


\begin{tabular}{lcc}
\multicolumn{1}{c}{$\begin{array}{c}\text { Tabel 3 } \\
\text { Hasil Uji Beda }\end{array}$} & \\
\hline Variabel & Sig. & Keterangan \\
\hline Kesadaran Lingkungan & 0,393 & Ditolak \\
Keterlibatan & 0,031 & Diterima \\
Lingkungan & & \\
Pelaporan Lingkungan & 0,002 & Diterima \\
Audit Lingkungan & 0,136 & Ditolak \\
\hline
\end{tabular}

Sumber: Data diolah sendiri (2018)

Berdasarkan tabel di atas, dapat disimpulkan bahwa hipotesis kedua dan ketiga diterima dan hipotesis pertama dan keempat ditolak. Hasil penelitian ini sedikit berbeda dengan penelitian yang dilakukan Astuti (2017) yaitu pada penelitiannya Kesadaran Lingkungan, Keterlibatan Lingkungan, dan Pelaporan Lingkungan tidak terdapat perbedaan yang signifikan pada Perguruan Tinggi di Wilayah Yogyakarta dan Surakarta. Sedangkan untuk variabel Audit Lingkungan, Astutui (2017) mengungkapkan hipotesisnya diterima bahwa terdapat perbedaan yang signifikan pada Perguruan Tinggi di Wilayah Yogyakarta dan Surakarta.

\section{KESIMPULAN DAN SARAN Kesimpulan}

Berdasarkan hasil penelitian yang telah dilakukan, dapat disimpulkan bahwa

1. Hasil uji beda untuk variabel Kesadaran Lingkungan adalah tidak terdapat perbedaan kesadaran lingkungan antara Universitas Riau Kepulauan dan Universitas Internasional Batam yang dapat dilihat nilai sig $0,393>0,05$ yang berarti hipotesis pertama (H1) ditolak.

2. Hasil uji beda untuk variabel Keterlibatan Lingkungan adalah terdapat perbedaan keterlibatan lingkungan antara Universitas Riau Kepulauan dan Universitas Internasional Batam yang dapat dilihat nilai sig $0,031<0,05$ yang berarti hipotesis kedua $(\mathrm{H} 2)$ diterima.

3. Hasil uji beda untuk variabel Pelaporan Lingkungan adalah terdapat perbedaan pelaporan lingkungan antara Universitas Riau Kepulauan dan Universitas Internasional Batam yang dapat dilihat nilai sig $0,002<0,05$ yang berarti hipotesis ketiga (H3) diterima.

Hasil uji beda untuk variabel Audit Lingkungan adalah tidak terdapat perbedaan audit lingkungan antara Universitas Riau Kepulauan dan Universitas Internasional Batam yang dapat dilihat nilai sig $0,136>0,05$ yang berarti hipotesis keempat (H4) ditolak.

\section{Keterbatan dan Saran Penelitian}

Keterbatasan dalam penelitian ini adalah penelitian in merupakan penelitian yang dilakukan dengan metode survey menggunakan kuesioner dalam pengambilan jawaban dari responden, sehingga penulis tidak mengawasi secara langsung atas pengisian jawaban tersebut. Berdasarkan hal tersebut, terdapat kemungkinan jawaban dari responden yang tidak mewakili keadaan yang sebenarnya yang disebabkan kondisi dan persepsi responden. Selain itu, sulitnya menentukan kriteria sampel sehingga menyebabkan sulitnya menentukan penentuan metode sampel dan terbatasnya responden serta lamanya durasi pengisian kuesioner yang menyebabkan penyelesaian penelitian relatif lama.

Saran untuk penelitian berikutnya adalah lebih mengembangkan variabel tentang akuntansi lingkungan yang mana pada penelitian variabel akuntansi lingkungannya hanya terbatas pada kesadaran lingkungan, 
keterlibatan lingkungan, pelaporan lingkungan, dan audit lingkungan.

\section{DAFTAR PUSTAKA}

Andriyanto, M. R. (2016). Pengawasan Implementasi "Green Accounting" Berbasis University Social Responsibility (USR) di Universitas Muhammadiyah Surakarta Serta Studi Komparasi Universitas Lain di Surakarta. Ekonomi \& Bisnis

Astiti, W. (2014). Implementasi Green Accounting Berbasis University Social Responsibility di Universitas Negeri Yogyakarta. Nominal, III, 134-194. Cohen , N., dan P. Robbins, (2011),Green Business : An A-to-Z Guide, Thousand Oaks, California: SAGE Publications Inc.

Dewan Standar Akuntansi Keuangan (DSAK), PSAK No.1 Penyajian Laporan Keuangan, 2009

Dewan Standar Akuntansi Keuangan (DSAK), PSAK No.57 Provisi Liabilitas Kontinjensi dan Aset Kontijensi, 2009 Kusumaningtias, R. (2013). Green Accounting, Mengapa dan Bagaimana?.

Proceeding Seminar Nasional dan Call for Papers Sancall, 137-149. Ministary of the Environtment Japan, Environmental Accounting Gudelines, 2005 Musyarofah, S. (2013). Analisis Penerapan Green Accounting di Kota Semarang.Accounting Analysis Journal ( Vol 2).

Pramanik, at.al ; (2007). Emironmental Accounting and Reporting, New Delhi, Deep Publication P.V.T ltd. Rocky Harris

Ratnawati. (2016). Implementasi Akuntansi Lingkungan sebagai Inovasi Mata Kuliah Program Studi Akuntansi. $M a-$ najemen dan Bisnis Jurnal, 2(1), 1-18.
Sari, M. P., \& Hadiprajitno, P., B. (2014). Pengawasan Implementasi "Green Accounting" berbasis University Social Responsibilities (USR) di Universitas Negeri Semarang. Akuntansi \& Auditing, 9(2), 169-198. 